\title{
Patologías del niño inmigrante en la Unidad de Cuidados Intensivos
}

\author{
Pathologies of the immigrant child in the Intensive Care Unit
Pamela Carrasco T. ${ }^{\text {a }}$, Fernando Bracho M. ${ }^{a}$, Soledad Montes F. ${ }^{a}$, Pablo Córdova L. ${ }^{a}$, Gianfranco Tomarelli R. ${ }^{a}$, Daniela Arriagada S. ${ }^{a}$, Alejandro Donoso F. ${ }^{a}$

a Unidad de Paciente Crítico Pediátrico. Hospital Dra. Eloísa Díaz I. La Florida. Santiago, Chile

Recibido: 28 de agosto de 2019; Aceptado: 23 de octubre de 2019

¿Qué se sabe del tema que trata este estudio?

En nuestro ambiente hospitalario, hasta hace poco tiempo, era infrecuente atender a niños inmigrantes. Existe información respecto a las distintas patologías que estos puedan presentar, por lo que consideramos importante familiarizar a nuestros médicos respecto a ellas.

\section{¿Qué aporta este estudio a lo ya conocido?}

El consistente aumento de la población migrante, conlleva nuevos desafíos en nuestros servicios de salud, por lo que nos parece importante actualizarnos respecto a las patologías infecciosas prevalentes y/o condiciones médicas al momento de enfrentar este tipo de pacientes.

\begin{abstract}
Resumen
Cada vez es más frecuente la atención médica en la Unidad de Cuidados Intensivos (UCI) de niños o adolescentes inmigrantes como también de aquellos nacidos en nuestro país con padres en tal condición. Esto ha ocasionado, en la actualidad, que el equipo de salud se deba enfrentar con problemas diagnósticos derivados del escaso conocimiento de condiciones genéticas propias de esta población y/o el desarrollo de diversas patologías infrecuentes en nuestro país, algunas resultantes de su condición sanitaria. En esta revisión se abordan diversos aspectos de la patología hematológica, infecciosa, parasitaria, respiratoria y cardiovascular, todos tópicos relevantes de conocer durante su estadía en la UCI. Es un deber del equipo de salud actualizarse sobre patologías de baja prevalencia en nuestro país, algunas de ellas muy poco conocidas hasta hace una década, pero que, actualmente, están cada vez más presentes en las UCI del sistema de salud público chileno.
\end{abstract}

Palabras clave: Inmigración; anemia; hemoglobinopatía; miocardiopatía; cuidados críticos 


\begin{abstract}
It is increasingly common to provide medical care in the Intensive Care Unit (ICU) for immigrant children and adolescents as well as those born in Chile with parents in such condition. Currently, this has caused that the health team has to face diverse infrequent pathologies in our country and/ or diagnostic problems derive from the poor knowledge of genetic conditions of this population, some resulting from their health conditions. This review addresses several aspects of hematological, infectious, parasitic, respiratory, and cardiovascular pathologies, all relevant topics to know during their stay in the ICU. It is a duty of the health team to be updated on pathologies of low prevalence in our country, some of them very little known until a decade ago, but which are currently increasingly present in the ICUs of the Chilean public health system.
\end{abstract}

\section{Keywords:}

Immigration; anemia; hemoglobinopathy; myocardiopathy; critical care

\section{Introducción}

En la última década, Chile ha experimentado un creciente aumento de la población inmigrante infantil, junto con modificación del origen de esta, siendo en la actualidad predominantemente desde países no limítrofes como Haití ${ }^{1}$, República Dominicana, Colombia y Venezuela ${ }^{2}$. Esto ha ocasionado que los médicos de la Unidad de Cuidados Intensivos (UCI) se deban enfrentar con problemas diagnósticos motivados por el limitado conocimiento de condiciones genéticas de esta población y/o el desarrollo de algunas patologías de escasa ocurrencia en nuestro país, lo que se intensifica por las barreras idiomáticas y culturales.

Debido al crecimiento de la población migrante en Chile, la incidencia de algunas enfermedades aumentará, ocasionando cambios epidemiológicos en la salud infantil ${ }^{3}$. No obstante, es de gran importancia destacar que la llegada de una población inmigrante no necesariamente implica una modificación en la situación epidemiológica, siempre que se mantengan los diversos programas nacionales de salud materno-infantil y de vigilancia epidemiológica, como también las campañas de prevención y la necesaria capacitación del personal sanitario ${ }^{2,4}$. Recientemente, la salud de los niños migrantes ha sido caracterizada, mostrando importantes brechas de desigualdad sanitaria $^{5}$.

El impacto de la inmigración en la pediatría nacional ya fue mencionado hace una década por VásquezDe Kartzow ${ }^{3}$, reconociéndolo como uno de los grandes retos a asumir, proponiéndonos una adecuada preparación ante la existencia de nuevas enfermedades en una sociedad multicultural.

El objetivo de la presente actualización es profundizar el conocimiento sobre el diagnóstico y tratamiento de algunas patologías del niño inmigrante críticamente enfermo.

\section{Anemia y hemoglobinopatías}

La anemia presenta una alta prevalencia en América Latina y el Caribe, estimándose una tasa global de $29 \%$ para los niños entre 6 y 59 meses, registrándose las cifras más altas en Haití $(65 \%)^{6}$. Esta puede ser causada por múltiples factores tanto ambientales (deficiencias nutricionales e infecciones) como también genéticos.

Las causas carenciales pueden ser de macro o micronutrientes (fierro, zinc, vitamina A, vitamina B12), siendo la más importante la anemia ferropriva. Como parte de las causas infecciosas, las parasitosis intestinales (anquilostomiasis, trichuriasis, esquistosomiasis) ${ }^{7} y$ la malaria son las etiologías más frecuentes (vide infra).

Dentro de los trastornos congénitos que causan anemia, las hemoglobinopatías (mutaciones cualitativas o cuantitativas de alguna de las cadenas de hemoglobina $[\mathrm{Hb}]$ ), principalmente las talasemias y la enfermedad de células falciformes (ECF), son las más relevantes de conocer por el médico de UCI.

Según distintos estudios epidemiológicos, la prevalencia en los países del Caribe de las mutaciones más frecuentes para hemoglobinopatías es variable; oscilando entre $3,7-11 \%$ para el estado heterocigotos de $\mathrm{HbS}$ (HbAS) y entre $0,3-0,52 \%$ para el estado homocigoto de $\mathrm{HbS}$ (HbSS) o ECF ; la mutación HbC fluctúa entre $2,5-4,7 \%$ para el estado heterocigoto ( $\mathrm{HbAC}$ ) y $0,1-$ $0,2 \%$ para la combinación con HbS (HbSC); la combinación de $\mathrm{HbS}$ y beta-talasemia (S $\beta$ ) es de $0,04 \%{ }^{8}$.

La migración ha tenido un efecto importante en la dispersión a nivel mundial de la ECF, como también para otras hemoglobinopatías, incluyendo $\mathrm{HbC}, \mathrm{HbE}$, $\mathrm{HbD}, \alpha$-talasemia y $\beta$-talasemia9 . La incorporación de migrantes portadores en países que originalmente no presentaban hemoglobinopatías ha determinado que aparezcan en grupos étnicos del lugar de destino ${ }^{10}$.

Los síndromes talasémicos corresponden a un grupo de hemoglobinopatías que se producen por la síntesis reducida o ausente de alguna de las cadenas 
normales de la hemoglobina, recibiendo el nombre $\alpha$ o $\beta$ talasemia, dependiendo de la cadena faltante. Los niños con talasemia suelen ser sanos al nacer, pero comienzan con sintomatología alrededor de los 6 meses de vida con una presentación clínica muy variable, siendo la más grave la anemia con requerimiento politransfusional ${ }^{11}$. Como resultado de estas, desarrollan sobrecarga de hierro multiorgánica, necesitando tratamiento quelante para evitar la toxicidad a largo plazo. Sin diagnóstico ni tratamiento, la mayoría muere de anemia o infecciones en los primeros años de vida ${ }^{11}$.

La ECF o drepanocitosis es la forma más frecuente de hemoglobinopatía estructural y consiste en una enfermedad multisistémica, que cursa con complicaciones tanto agudas como crónicas ${ }^{12}$. El principal fenómeno patogénico es la tendencia de la $\mathrm{HbS}$ a formar polímeros, que determinan un cambio conformacional y una mayor rigidez de los eritrocitos (drepanocitos), dependiendo del grado de oxigenación celular, la concentración intracelular de $\mathrm{Hb}$ y la presencia de $\mathrm{HbF}$; esto provoca que los eritrocitos no puedan transitar normalmente por la microcirculación, aumentando así la viscosidad sanguínea ${ }^{13}$.

Esta se caracteriza por presentar desde los 2 a 4 meses de vida anemia hemolítica, episodios de hemólisis y/o vaso-oclusivos (isquemia y microinfartos), que determinan la aparición de anemia, crisis de dolor por oclusión vascular y un mayor riesgo de infecciones bacterianas invasivas (asplenia funcional) ${ }^{13}$. Las manifestaciones más frecuentes durante la infancia son las crisis vaso-oclusivas óseas (dactilitis o de huesos largos), síndrome torácico agudo (STA) en adolescentes, secuestro esplénico agudo (infrecuente pero potencialmente fatal por shock hipovolémico) (figura 1), accidente cerebro-vascular (ACV), convulsiones e infecciones por pérdida de la función reticuloendotelial esplénica ${ }^{13}$. La falla renal y cardíaca son más frecuentes en adultos.

Para su tratamiento existen guías clínicas que resumen las medidas recomendadas para prevenir y tratar estas complicaciones ${ }^{12,14}$. A su ingreso a la UCI, tanto para la drepanocitosis homocigota como para la heterocigota compuesta, se debe asegurar desde un inicio hiperhidratación, adecuada oxigenación, control del dolor e inicio precoz de antibioticoterapia en pacientes febriles. La transfusión de glóbulos rojos se indica para valores de $\mathrm{Hb}<5 \mathrm{~g} / \mathrm{dL}$, salvo existencia de elementos de disoxia. No se debe superar valor de hematocrito (Hto) en $30 \%$.

La exanguinotransfusión tiene el objetivo de disminuir el porcentaje de $\mathrm{HbS}$ a $<30 \%$ y se debe considerar en ACV, STA, shock séptico, previo a procedimientos invasivos y/o quirúrgicos ${ }^{15}$. Respecto a esta última indicación, tanto la anestesia como la cirugía incrementan el riesgo de complicaciones, particularmente el
STA $^{15}$. Como medida preoperatoria es trascendente la hiperhidratación; durante la cirugía es importante evitar la hipotermia y en el postoperatorio debe lograrse una correcta analgesia, promover la deambulación precoz y realizar manejo kinésico respiratorio para prevenir el desarrollo de atelectasias (precipitan crisis vaso-oclusivas $)^{12}$.

Ambas modalidades de exanguinotransfusión (manual y automatizada) son por igual eficientes en la disminución de la $\mathrm{HbS}^{16}$. Esta se puede realizar con concentrado de hematíes (reconstituido con solución fisiológica o albúmina) o con sangre total, siendo más ventajosa la primera al lograr una pronta disminución de la HbS. Se debe intercambiar entre un 100-125\% de la masa eritrocitaria ${ }^{17}$ (tabla 1). Posterior al procedimiento, se debe medir el porcentaje de HbS mediante electroforesis de hemoglobina o cromatografía líquida

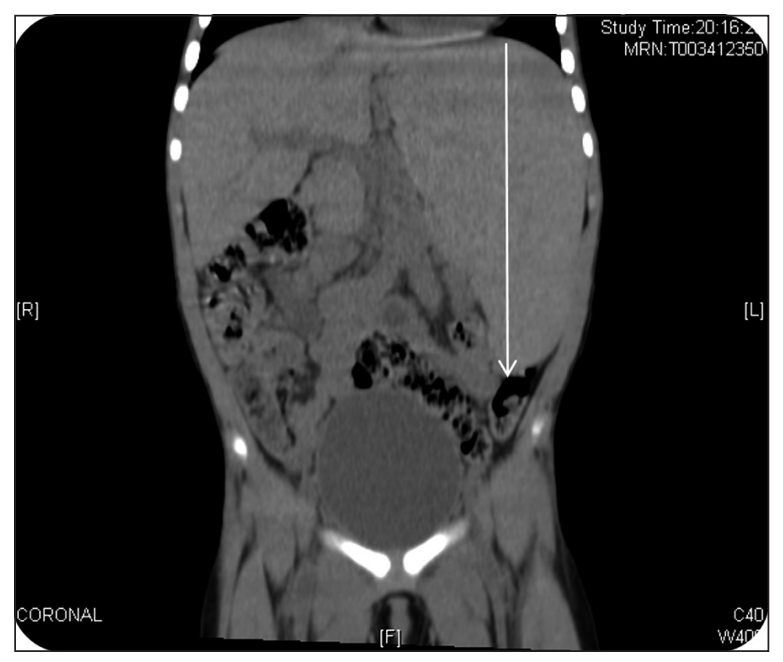

Figura 1. Tomografía computarizada de abdomen en paciente de 7 años con diagnóstico de hemoglobinopatía heterocigota ( $\mathrm{HbS} /$ Beta-Talasemia). Se observa bazo aumentado de tamaño con diámetro longitudinal máximo de $15 \mathrm{~cm}$ (flecha blanca) y peso estimado de $950 \mathrm{~g}$.

Tabla 1. Propuesta de procedimiento a realizar para exanguinotransfusión manual en paciente con enfermedad de células falciformes (Modificado de Swerdlow PS ${ }^{17}$ )

Cálculo de masa eritrocitaria a recambiar: 1- 1,25 x (Hto x volumen sanguíneo total). Volumen sanguíneo total: $70 \mathrm{ml} / \mathrm{kg}$ en $>20 \mathrm{~kg}$ y 85 $\mathrm{ml} / \mathrm{kg}$ en $<20 \mathrm{~kg}$

Extraer $5-10 \mathrm{ml} / \mathrm{kg}$ de sangre

Infundir 5-10 $\mathrm{ml} / \mathrm{kg}$ de solución fisiológica

Extraer $5-10 \mathrm{ml} / \mathrm{kg}$ de sangre

Infundir 5-10 ml/kg de glóbulos rojos

Repetir pasos 2, 3, 4 y 5 hasta haber logrado recambiar la masa eritrocitaria calculada

Hto:hematocrito 
de alta resolución ${ }^{15}$, o en su defecto se han propuesto fórmulas para su estimación ${ }^{18}$.

La mortalidad de la ECF sin tratamiento es mayor al $90 \%$ antes de los 5 años de vida, siendo las causas más frecuentes infecciones, STA y ACV ${ }^{19}$.

El STA es la principal causa de ingreso a UCI y muerte en niños con ECF. Este se diagnostica por la presencia de nuevos infiltrados radiológicos pulmonares asociados a signos de falla respiratoria aguda. Los agentes causantes más frecuentes son la infección e infarto pulmonar y la embolia grasa. Finalmente, se describen dentro de los factores asociados para el uso de ventilación mecánica invasiva en el STA la existencia de comorbilidades como obesidad, apnea obstructiva del sueño y enfermedad cardíaca ${ }^{20}$.

\section{Tuberculosis}

Según la Organización Mundial de la Salud (OMS), Chile tuvo una incidencia de 16/100.000 habitantes en el año 2017, valor muy menor al compararlo con otros países como Haití (181), Perú (116), Bolivia (111) y Venezuela $(42)^{21}$. En el año 2016, el 11\% de los casos de tuberculosis (TBC) infantil en Chile se produjeron en niños extranjeros.

Se debe sospechar TBC en niños con antecedentes de contacto con adulto con TBC pulmonar, pacientes con tos de más de 15 días de evolución asociado a síntomas consuntivos y/o hemoptisis, en pacientes con virus de inmunodeficiencia humana (VIH) con síndrome febril y aparición de imágenes pulmonares, en neumonía de evolución tórpida y/o resistente a tratamiento antibiótico y en pacientes con imágenes pulmonares o mediastínicas persistentes.

\section{Dengue}

Es una enfermedad viral (virus DEN) transmitida por la picadura del mosquito Aedes aegypti. Se presenta de diferentes formas, desde enfermedad leve hasta fiebre hemorrágica por dengue (FHD). Se describe que entre 1 a $5 \%$ de los pacientes pueden presentar manifestaciones graves. El dengue grave es más frecuente en personas que padecieron la enfermedad previamente (infección primaria) por un serotipo y se infectan nuevamente con un serotipo diferente (infección secundaria). No obstante, se debe señalar que no necesariamente toda infección secundaria ocasiona dengue grave $^{22}$.

La mayoría de las infecciones se presentan sin síntomas o en forma oligosintomática. En lactantes habitualmente es asintomática (80\%). El dengue o dengue clásico corresponde a una enfermedad febril aguda

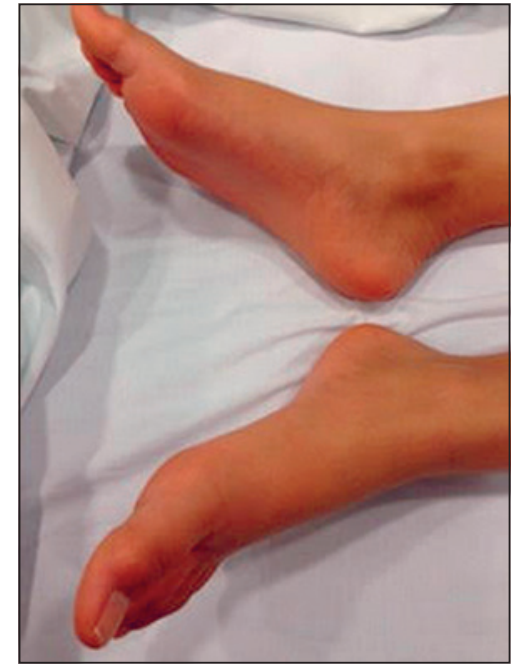

Figura 2. Exantema escarlatiniforme plantar en paciente con diagnóstico de dengue.

$\left(\geq 39^{\circ} \mathrm{C}\right)$ acompañada de malestar general, cefalea, mialgias, exantema (figura 2), dolor retro-ocular y articular. Los síntomas se inician 4 a 7 días posterior a la picada del mosquito infectado. El período de incubación varía desde 3 a 14 días, por lo que se puede descartar dengue en el paciente que lleva más de 14 días de regreso desde un país endémico.

La manifestación más peligrosa es la FHD, que se asocia a disfunción hemodinámica con shock. Sus principales características son: aumento de la permeabilidad vascular evidenciada por hemoconcentración, derrame pleural, ascitis, derrame pericárdico, y trombocitopenia con sangrado espontáneo (tabla 2). El aumento de la permeabilidad capilar se desarrolla 24-48 horas luego de la caída de la fiebre.

No se dispone de terapia antiviral y el tratamiento consiste en soporte vital según el escenario clínico, para lograr una adecuada estabilidad hemodinámica. El tratamiento del dengue grave difiere de la sepsis bacteriana, principalmente en lo referente a la reanimación con fluidos. Se debe evitar un exceso de aportes e idealmente debe monitorizarse mediante hemodinamia funcional para evitar complicaciones por sobrecarga hídrica. Algunas consideraciones terapéuticas son: no usar antiinflamatorios no esteroidales para el tratamiento de la fiebre, transfusión sólo en caso de hemorragia activa y recuento de plaquetas $<10.000 / \mathrm{mm}^{3}$. No está recomendado el uso de terapia esteroidal ${ }^{23}$. Finalmente, no existe evidencia para recomendar un tipo de fluido por sobre otro en el paciente hipotenso.

\section{Malaria}

La malaria es una infección sistémica producida por el parásito Plasmodium ( $P$. vivax, P. falciparum, 
Tabla 2. Elementos clínicos y de laboratorio para el reconocimiento precoz de fiebre hemorrágica por dengue o dengue grave

Duración de la enfermedad: el riesgo máximo de shock es entre los 3-7 días del inicio de los síntomas, que generalmente coincide con la caída de la fiebre. La pérdida de plasma usualmente se presenta 24 horas antes y 24 horas después de la caída de la fiebre

Signos de alarma: dolor abdominal grave, vómitos persistentes, letargia/agitación, hipotermia, sangrado, palidez, hepatomegalia. Hematocrito: si aumenta ( $\geq 20 \%$ ), traduce pérdida de plasma

Plaquetas: niveles $<100.000 / \mathrm{mm}^{3}$ precede a la pérdida de plasma

SGOT: el aumento de los niveles se puede presentar en todas las formas de infección por virus dengue, sin embargo, su mayor elevación se asocia principalmente a FHD

Nivel plasmático de NS1: niveles $>600 \mathrm{ng} / \mathrm{ml}$ se asocia a FHD

Presencia de otras enfermedades asociadas.

NS1: antígeno NS1 del virus del dengue; SGOT: aspartato aminotransferasa; FHD: Fiebre hemorrágica por dengue.

P. malariae y P. ovale), transmitido por la picadura de mosquitos de la familia Anopheles. En América Latina, donde existe endemia de $P$. vivax y $P$. falciparum, la incidencia de paludismo y su letalidad disminuyeron progresivamente entre el año 2006 y el 2014, pero desde el 2015 se ha notificado un aumento en varios países, la mayoría endémicos, dentro de los cuales se encuentran Colombia, Haití, Venezuela y Perú. El 90\% de los casos importados reportados en América durante el 2016 tuvieron origen en esos cuatro países, dentro de los cuales destacan Venezuela y Perú.

Cualquier paciente con permanencia en un área endémica en las semanas previas al inicio de los síntomas (habitualmente inespecíficos), debe ser evaluado por la eventual existencia de esta enfermedad. El periodo de incubación fluctúa entre 9 y 18 días para el $P$. falciparum (agente más común de la malaria grave), aunque este es variable y la sintomatología puede aparecer incluso meses después. La fiebre y calofríos son los síntomas más frecuentemente reportados, así como la presencia de esplenomegalia al examen físico. En el laboratorio destaca anemia, trombopenia e hiperbilirrubinemia. Es vital el tratamiento precoz, existiendo distintas alternativas terapéuticas según gravedad y resistencia farmacológica ${ }^{24}$. El empleo de exanguinotransfusión es controvertido, presentando recomendaciones específicas como son nivel de parasitemia $>10 \%$, malaria cerebral o disfunción orgánica.

\section{Neurocisticercosis}

La neurocisticercosis (NCC) es una entidad endémica en América Central y del Sur, siendo reconocida como la infección parasitaria más común del sistema nervioso central y principal causa de epilepsia ${ }^{25}$. Revisiones sistemáticas la describen como causa entre el 30 a $40 \%$ de los pacientes epilépticos en regiones endémicas $^{26}$. La NCC tiene un periodo de latencia entre 2 a 5 años y su sintomatología dependerá del número, localización y etapa de los quistes, como también de la respuesta inmune del huésped. Los quistes parenquimatosos son los más frecuentes $(60 \%)$, siendo la actividad epiléptica su forma más habitual de manifestación. La presencia de múltiples quistes con edema cerebral puede simular una encefalitis, lo que es frecuente de observar en niños. Una reciente revisión ha actualizado sus criterios diagnósticos ${ }^{27}$. Además de las medidas de neuroprotección necesarias, la recomendación vigente para el tratamiento de la NCC parenquimatosa activa es el uso de albendazole más esteroides. Previo al uso de terapia esteroidal se debe descartar tuberculosis y estrongiloidiasis por el riesgo de diseminación asociado a su uso ${ }^{28}$.

\section{Estrongiloidiasis}

Es una parasitosis subdiagnosticada, que presenta un carácter endémico en regiones de clima tropical y subtropical, siendo considerada por la OMS dentro del listado de las "enfermedades tropicales menospreciadas" 29 . Aunque es una patología infrecuente y poco conocida en Occidente, debe ser considerada, incluso tiempo después de haber estado en zonas endémicas.

Es producida por el nemátodo Strongyloides stercoralis (Ss), cuya larva filariforme (L3) es la forma infectante para el hospedero humano. La mayoría de los pacientes infectados permanecen asintomáticos, siendo la eosinofilia su único hallazgo. Las manifes- 
taciones clínicas pueden ser cutáneas (larva currens), respiratorias, gastrointestinales ${ }^{30} \mathrm{y}$, excepcionalmente, puede ocurrir el síndrome de hiperinfección, el cual corresponde a una estrongiloidiasis diseminada con sobreinfección bacteriana sistémica, habitualmente en un huésped con inmmunocompromiso celular ${ }^{28}$. En estos pacientes es frecuente el aislamiento de múltiples bacterias, lo que es secundario a la pérdida de la función de barrera (digestiva y pulmonar).

La autoinfección es posible luego de la infestación inicial del paciente, resultando en un estado infeccioso crónico, habitualmente asintomático. Sin embargo, ante un episodio transitorio de inmunodeficiencia puede desarrollarse una acelerada diseminación extraintestinal.

Su principal factor de riesgo es el uso de terapia inmunosupresora, fundamentalmente corticoides sistémicos, los cuales exacerban el paso de larvas no infectivas a filariformes. Otros factores descritos son la desnutrición grave y la coinfección con el virus HTLV1 (Human T-cell lymphotropic virus -1).

Se han descrito reportes de casos de disfunción orgánica múltiple asociada a estrongiloidiasis diseminada, entidad con elevada mortalidad ${ }^{31}$.

Considerando que es una parasitosis de difícil diagnóstico ${ }^{30}$, el reconocimiento precoz de la enfermedad y el tratamiento efectivo con terapia antihelmíntica (ivermectina y tiabendazol) se asocia a un mejor pronóstico.

\section{Virus de inmunodeficiencia humana}

Se conocen determinadas zonas geográficas (variación regional) como un factor de riesgo independiente para la adquisición de $\mathrm{VIH}$, lo que origina un desafío en los sistemas de salud del país receptor ${ }^{32}$.

La mayor prevalencia del VIH en la poblacion migrante, está asociada a las diversas barreras a las cuales se ven enfrentados para poder acceder oportunamente a los servicios sanitarios, incluyendo factores a nivel estructural (vulnerabilidad social, racismo y xenofobia), del sistema de salud (falta de servicios adaptados lingüística y culturalmente) y comunitaria (normas culturales). Como consecuencia, los pacientes migrantes tienen mayor probabilidad de un diagnóstico tardío, ausencia de soporte social y eventual abandono de la terapia ${ }^{33}$.

El principal impacto ha sido en la salud maternoinfantil ${ }^{34}$, ya que frecuentemente se busca apoyo médico en estados avanzados de gravidez, dificultando un diagnóstico y tratamiento precoz que impida la transmisión vertical. Esta nueva realidad plantea retos específicos en relación con las necesidades y utilización de los servicios de salud ${ }^{4}$.

\section{Crisis asmática}

Se ha evidenciado que los pacientes afrodescendientes (específicamente afroamericanos) son más susceptibles de presentar episodios asmáticos de mayor gravedad $^{35}$, sin embargo, la condición socioeconómica y ambiental, principalmente reflejada por una baja adherencia terapéutica y existencia de contaminación intradomiciliaria, juega un rol trascendental ${ }^{36}$. Aún no está establecido si al eliminarlas, las diferencias se mantienen o pudieran existir factores genéticos que expliquen por sí solos su mayor susceptibilidad, gravedad, respuesta terapéutica y mortalidad.

Un estudio en población adulta asmática ${ }^{37}$, demostró que pacientes afrodescendientes presentaban una variante poco común del gen ADRB2 (receptor $\beta 2$ adrenérgico) versus caucásicos, lo cual se correlacionó con un peor pronóstico para el uso de $\beta$ agonistas de larga duración. Recientemente, Grunwell et al..$^{38}$ identificaron en niños asmáticos diferencias raciales asociadas con una mayor probabilidad de ingreso a UCI, lo que sugiere la existencia de factores de riesgo ligados con una crisis asmática distintos de los tradicionalmente empleados para su evaluación (a futuro, genotipificación del niño con asma grave). En la misma línea, se han identificado polimorfismos genéticos para el receptor $\beta 2$-adrenérgico que pudiesen ser considerados al momento de elegir la terapia óptima en el niño con status asmático ${ }^{39}$. Queda aún pendiente establecer si estos hallazgos son extrapolables para la población afrocaribeña.

\section{Patología cardiovascular}

La patología cardíaca originada por déficit nutricional puede deberse a deficiencia de vitamina $\mathrm{D}$, que se presenta como miocardiopatía dilatada y, en ocasiones, cursa sin sintomatología de hipocalcemia grave o evidencia radiológica de raquitismo ${ }^{40}$.

La ECF se asocia con un gasto cardíaco elevado en reposo y cardiomegalia ${ }^{41}$. La combinación de anemia crónica y la resultante sobrecarga de fluidos por hemodilución, origina un aumento compensatorio tanto de las dimensiones del ventrículo izquierdo (VI) como de su masa, siendo estas proporcionales a la magnitud de la anemia. No obstante, el aumento de la precarga, no produce alteración en la función sistólica ${ }^{42,43}$.

Se debe tener en cuenta que los valores "normales" de las dimensiones ventriculares empleados para la población general no son extrapolables en estos pacientes, siendo evidente el aumento de tamaño desde los dos años de edad ${ }^{43}$.

Estudios cintigráficos han revelado una alteración en la perfusión miocárdica, la cual no se ha visto reflejada en la contractilidad global o segmentaria ${ }^{41}$. 
En muchos pacientes, la existencia de hipertrofia ventricular y disfunción diastólica se correlaciona con el tiempo de evolución de la enfermedad. Sin embargo, Caldas et al. ${ }^{44}$ demostraron anormalidades precoces en la función diastólica aún en etapas iniciales de la ECF.

Se ha confirmado en pacientes con ECF, la ausencia de siderosis cardíaca, incluso en sujetos con una significativa carga transfusional y sobrecarga sistémica de hierro ${ }^{45}$. Asimismo, se investigó la relación entre la carga de hierro, el depósito de hierro miocárdico y la disfunción ventricular diastólica en niños, no encontrándose relación alguna. La disfunción mencionada fue más bien el resultado de la gravedad de la enfermedad $^{46}$.

Se debe tener un alto índice de sospecha para el diagnóstico diferencial entre infarto miocárdico y crisis vaso-oclusiva. Cambios electrocardiográficos consistentes con isquemia miocárdica son frecuentes de encontrar en niños con ECF, en especial durante las crisis $^{47}$. Se ha propuesto la evaluación mediante un simple sistema de puntaje derivado del análisis electrocardiográfico, para reconocer precozmente la existencia y gravedad de la isquemia miocárdica ${ }^{48}$.

Otra complicación descrita en los pacientes con ECF es la hipertensión pulmonar ocasionada por hemólisis intravascular persistente, la cual descompartimentaliza la $\mathrm{Hb}$ y la arginasa-1 eritrocitaria, captando óxido nítrico (NO) y su precursor L-arginina, ocasionando así una reducción en su biodisponibilidad, particularmente en pacientes con una elevada tasa hemolítica ${ }^{49}$. Una casuística en un grupo de pacientes (11.7 \pm 4.7 años) no evidenció ecocardiográficamente hipertensión pulmonar significativa, no obstante, una menor magnitud de esta no puede ser descartada con esta modalidad diagnóstica ${ }^{42}$.

Con el aumento de la sobrevida de los pacientes con ECF las complicaciones cardiovasculares serán más frecuentes, especialmente la vasculopatía proliferativa sistémica, hipertensión pulmonar y disfunción diastólica del $\mathrm{VI}^{50}$.

\section{Discusión}

Las patologías presentes en la población inmigrante, además de aquellas determinadas genéticamente, abarcan un amplio espectro. Muchas de ellas están relacionadas con su precariedad sociosanitaria, condición que habitualmente se mantiene en el país de destino $^{3}$.

En el ámbito extrahospitalario, el niño inmigrante puede ver en riesgo su salud dado que, ante la presencia de morbilidad aguda, existe demora tanto en su diagnóstico como tratamiento, pues consulta menos y en forma más tardía además del no cumplimiento de indicaciones médicas ${ }^{3,5}$.

Una vez ingresado a la UCI, puede en ocasiones existir retraso diagnóstico y/o terapéutico debido al escaso conocimiento de algunas de las patologías como las aquí revisadas. Para ayudar a mitigar esta falencia se recomienda evaluar rutinariamente su condición nutricional y efectuar la búsqueda de estados carenciales; considerar la existencia de hemoglobinopatías, su evolución clínica y eventuales complicaciones cardiovasculares, infecciosas, pulmonares y neurológicas, las cuales pueden empeorar la evolución de la enfermedad que motivó su admisión. El grupo de enfermedades infecciosas deben ser sospechadas y/o descartadas según el contexto epidemiológico del niño.

Es un deber del equipo de salud disponer, para algunas de estas enfermedades, de pautas de tratamiento validadas localmente como también de una actualización permanente sobre patologías de baja prevalencia en nuestro país, algunas de ellas muy poco conocidas hasta hace una década, pero que, en la actualidad, son cada vez más habituales en las UCI del sistema de salud público chileno.

\section{Conflicto de intereses}

Los autores declaran no tener conflicto de intereses.

\section{Referencias}

1. Sánchez K, Valderas J, Messenger K, Sánchez C, Barrera F. Haití, la nueva comunidad inmigrante en Chile. Rev Chil Pediatr. 2018;89(2):278-83.

2. Vásquez-De Kartzow R. La nueva ola de inmigración en Chile. Oportunidad para crecer como país. Rev Chil Pediatr. 2018;89(3):307-9.

3. Vásquez-De Kartzow R. Impacto de las migraciones en Chile: Nuevos retos para el pediatra. ¿Estamos preparados? Rev Chil Pediatr. 2009;80(2):161-7.

4. Vásquez-De Kartzow R. Viejos y nuevos actores de la epidemiología en tiempos de globalización. Rol de los inmigrantes. En: Migraciones, salud y globalización: Entrelazando miradas. OIM, Ministerio de Salud, OPS. Santiago, Chile. 2010;2536.

5. Cabieses B, Chepo M, Oyarte M, et al. Brechas de desigualdad en salud en niños migrantes versus locales en Chile. Rev Chil Pediatr. 2017;88(6):707-16.

6. Organización de las Naciones Unidas para la Alimentación y la Agricultura y la Organización Panamericana de la Salud. Panorama de la seguridad alimentaria y nutricional 2016. ISBN 978-92-5-309608-
4, FAO y OPS, 2017.

7. Iannotti L, Delnatus J, Odom A, et al. Determinants of anemia and hemoglobin concentration in Haitian schoolaged children. Am J Trop Med Hyg. 2015;93:1092-8.

8. Rotz S, Arty G, Dall'Amico R, De Zen L, Zanolli F, Bodas P. Prevalence of sickle cell disease, hemoglobin S, and hemoglobin $\mathrm{C}$ among Haitian newborns. Am J Hematol 2013;88(9):827-8.

9. Piel FB, Tatem AJ, Huang Z, Gupta S, Williams TN, Weatherall DJ. Global migration and the changing distribution of sickle haemoglobin: a quantitative 
study of temporal trends between 1960 and 2000. Lancet Glob Health 2014;2(2):e80-9.

10. Stretly A, Latinovic R, Henthorn J. Positive screening and carrier results for the England-wide universal newborn sickle cell screening programme by ethnicity and area for 2005-07. J Clin Pathol 2010; 63:626-9.

11. Martin A, Thompson AA. Thalassemias. Pediatr Clin N Am. 2013;60(6):1383-91.

12. Rives Solà $S$. Enfermedad de células falciformes; papel del pediatra. An Pediatr Contin 2013;11(3):123-31.

13. Quinn CT. Sickle Cell Disease in Childhood. From Newborn Screening Through Transition to Adult Medical Care. Pediatr Clin N Am 2013; 60(6):1363-81.

14. National Institute of Health. EvidenceBased Management of Sickle Cell Disease. Expert Panel Report, 2014: Guide to Recommendations. NIH 2014. Disponible en https://www.nhlbi.nih. gov/sites/default/files/media/docs/sicklecell-disease-report\%20020816_0.pdf. Accedido el día 4 de febrero del 2019

15. Biller E, Zhao Y, Berg M, et al. Red blood cell exchange in patients with sickle cell disease-indications and management: a review and consensus report by the therapeutic apheresis subsection of the AABB. Transfusion. 2018;58(8):1965-72.

16. Otrock ZK, Thibodeaux SR, Jackups R Jr. Vascular access for red blood cell exchange.Transfusion. 2018;58 Suppl 1:569-79.

17. Swerdlow PS. Red cell exchange in sickle cell disease. Hematology Am Soc Hematol Educ Program. 2006: 48-53.

18. Keiser AM, Booth GS, Gehrie EA. With a simple calculation, the fraction of platelets remaining can be used to estimate the residual hemoglobin $\mathrm{S}$ percentage in sickle cell disease patients undergoing automated red blood cell exchange. Transfus Apher Sci. 2018;57(2):250-2.

19. Piel FB, Steinberg MH, Rees DC. Sickle Cell Disease. N Engl J Med. 2017; 376:1561-73.

20. Akahashi T, Okubo Y, Pereda MA, Handa A, Miller S. Factors Associated with Mechanical Ventilation Use in Children with Sickle Cell Disease and Acute Chest Syndrome. Pediatr Crit Care Med 2018;19:801-9.

21. OMS Tuberculosis: perfiles de países. Disponible en https://www.who.int/tb/ country/data/profiles/es/. Accedido el día 15 de febrero de 2019.

22. Simmons CP, Farrar JJ, Nguyen vV, Wills B. Dengue. N Engl J Med. 2012; 366:142332.

23. Dondorp AM, Hoang MNT, Mer M; Sepsis in Resource-Limited SettingsExpert Consensus Recommendations
Group of the European Society of Intensive Care Medicine (ESICM) and the Mahidol-Oxford Research Unit (MORU) in Bangkok, Thailand Recommendations for the management of severe malaria and severe dengue in resource-limited settings. Intensive Care Med. 2017; 43:1683-5.

24. Cohee LM, Laufer MK. Malaria in children. Pediatr Clin North Am. 2017; 64(4):851-66.

25. Thompson H, Thakur K. Infections of the central nervous system in returning travelers and immigrants. Curr Infect Dis Rep 2017; 19(11):45.

26. Burneo JG, Cavazos JE. Neurocysticercosis and epilepsy. Epilepsy Curr. 2014;14(1 Suppl):23-8.

27. Del Brutto OH, Nash TE, White AC Jr, et al. Revised diagnostic criteria for neurocysticercosis. J Neurol Sci. 2017; 372:202-10

28. Lam CS, Tong MK, Chan KM, Siu YP. Disseminated strongyloidiasis: a retrospective study of clinical course and outcome. Eur J Clin Microbiol Infect Dis. 2006;25(1):14-8.

29. Organización Mundial de la Salud. Soiltransmitted helminth infections. Marzo 2016. Disponible en: http://www.who. $\mathrm{int} /$ mediacentre/ factsheets/fs366/en/. Accedido el día 25 de marzo de 2019.

30. Gonzalez A, Gallo M, Valls ME, et al. Clinical and epidemiological features of 33 imported Strongyloides stercoralis infections. Trans R Soc Trop Med Hyg. 2010;104:613-6.

31. Pérez F, Núñez F, Niurys M, Cabrera R, Rodríguez E. Falla orgánica múltiple por estrongiloidiasis diseminada: Comunicación de un caso. Rev Chil Infectol. 2012;29(3):344-7.

32. Rebolledo-Ponietsky K, Munayco CV, Mezones-Holguín E. Migration crisis in Venezuela: impact on HIV in Peru. J Travel Med. 2019;26(2). pii: tay155.

33. Cabieses B, Gálvez P, Ajraz N. International migration and health: the contribution of migratory social theories to public health decisions. Rev Peru Med Exp Public Health. 2018;35(2):285-91.

34. Izquierdo G, Reyes A, Delpiano L, et al. Inmigración e impacto en la infectología de recién nacidos. Rev Chilena Infectol. 2017;34(4):374-6.

35. Newth C, Meert K, Clark A, et al. Fatal and near-fatal asthma in children: the critical care perspective. J Pediatr.2012;161:214-21.e3.

36. Alexander D, Currie J. Is it who you are or where you live? Residential segregation and racial gaps in childhood asthma. J Health Econ. 2017;55:186-200.

37. Ortega V, Hawkins G, Moore W, et al. Effect of rare variants in ADRB2 on risk of severe exacerbations and symptom control during long acting $\beta$ agonist treatment in a multiethnic asthma population: a genetic study. Lancet Respir Med 2014;2(3):204-13.

38. Grunwell JR, Travers C, Fitzpatrick AM. Inflammatory and comorbid features of children admitted to a PICU for status asthmaticus. Pediatr Crit Care Med. 2018;19(11):e585-94.

39. Elbahlawan L, Binaei S, Christensen ML, Zhang Q, Quasney MW, Dahmer MK. Beta2-adrenergic receptor polymorphisms in African American children with status asthmaticus. Pediatr Crit Care Med. 2006;7(1):15-8.

40. Polat V, Bozcali E, Uygun T, Opan $S$, Karakaya O. Low vitamin D status associated with dilated cardiomyopathy. Int J Clin Exp Med. 2015;8(1):1356-62.

41. Voskaridou E, Christoulas D, Terpos E. Sickle-cell disease and the heart: review of the current literature. Br J Haematol. 2012;157(6):664-73.

42. Batra AS, Acherman RJ, Wong WY, et al. Cardiac abnormalities in children with sickle cell anemia. Am J Hematol. 2002;70:306-12.

43. Lester LA, Soft PC, Hutcheon N, Arcilla RA. Cardiac abnormalities in children with sickle cell anemia. Chest 1990;98(5):1169-74

44. Caldas M, Meira Z, Barbosa M. Evaluation of 107 patients with sickle cell anemia through tissue Doppler and myocardial performance index. J Am Soc Echocardiogr. 2008;21(10):1163-7.

45. Inati A, Musallam KM, Wood JC, Sheikh-Taha M, Daou L, Taher AT. Absence of cardiac siderosis by MRI T2* despite transfusion burden, hepatic and serum iron overload in Lebanese patients with sickle cell disease. Eur J Haematol. 2009;83(6):565-71.

46. Hankins JS, McCarville MB, Hillenbrand $\mathrm{CM}$, et al. Ventricular diastolic dysfunction in sickle cell anemia is common but not associated with myocardial iron deposition. Pediatr Blood Cancer. 2010;55(3):495-500.

47. de Montalembert M, Maunoury C, Acar P, Brousse V, Sidi D, Lenoir G. Myocardial ischaemia in children with sickle cell disease. Arch Dis Child. 2004;89(4):359-62.

48. Bode-Thomas F, Hyacinth H, Ogunkunle $\mathrm{O}$, Omotoso A. Myocardial ischaemia in sickle cell anaemia: evaluation using a new scoring system. Ann Trop Paediatr. 2011;31(1):67-74.

49. Morris CR, Kato GJ, Poljakovic M, et al. Dysregulated arginine metabolism, hemolysis-associated pulmonary hypertension, and mortality in sickle cell disease. JAMA. 2005;294(1):81-90.

50. Gladwin MT, Sachdev V. Cardiovascular abnormalities in sickle cell disease. J Am Coll Cardiol. 2012;59(13):1123-33. 